\title{
Ciclos televisivos de ficción en episodios unitarios: crítica y resistencia al régimen dictatorial argentino
}

\author{
Anthology Television Series: Criticism and Resistance \\ to the Argentine Dictatorial Regime
}

\author{
https://doi.org/10.22235/d34.2268 \\ Ana Laura Lusnich \\ ORCID: 0000-0001-6612-4864 \\ Consejo Nacional de Investigaciones Científıcas y Técnicas (CONICET). \\ Universidad de Buenos Aires. Argentina.
}

\section{RESUMEN}

En este artículo se analiza un conjunto de ciclos televisivos de ficción compuestos por episodios unitarios y emitidos en la Argentina en la última dictadura cívico-militar (19761983), con el objetivo de constatar la demarcación de un espacio alternativo de creación-expresión. En primer lugar, se aborda la constitución de un tejido artístico-creativo que obró proactivamente en la concreción de los ciclos. En segundo lugar, se estudian las características textuales de estos programas y su apuesta por modalidades narrativas y espectaculares que facilitaban abordar críticamente problemáticas relacionadas con el presente histórico. Finalmente se indaga en la producción de sentido, en la cual el efecto de corpus y la recepción cómplice de los espectadores adquieren vital protagonismo. Se concluye que los ciclos estudiados se distanciaron de la programación televisiva de la época y configuraron una experiencia que obró en disidencia al régimen, postulando la crítica y la resistencia a sus lineamientos ideológicos y prácticas políticas.

Palabras clave: Argentina; dictadura; resistencia; televisión; ciclos televisivos de ficción; episodios unitarios.

\begin{abstract}
This article analyzes a group of anthology television series broadcasted in Argentina during the last civil-military dictatorship (1976-1983), with the aim of confirming the demarcation of an alternative space of creation-expression. First, we address the constitution of an artistic-creative fabric that worked proactively in the realization of the cycles. Secondly, we study the textual characteristics of these programs and their commitment to narrative and spectacular modalities that facilitated a critical approach to issues related to the historical present. Finally, the production of meaning is investigated, in which the corpus effect and the complicit reception of the viewers acquire vital prominence. It is concluded that the cycles studied distanced themselves from the television programming of the time and configured an experience that worked in dissidence to the regime, postulating criticism and resistance to its ideological guidelines and political practices.

Keywords: Argentina; dictatorship; resistance; television; fiction television cicles; anthology television series.
\end{abstract}

Cómo citar: Lusnich, A. L. (2021). Ciclos televisivos de ficción en episodios unitarios: critica y resistencia al régimen dictatorial argentino. Dixit, 34, 48-62. https://doi.org/10.22235/d34.2268

Recepción: 10/09/2020 :: Revisión: 27/01/2021 :: Aceptación: 04/02/2021 


\section{Introducción}

Las investigaciones realizadas en los últimos decenios han dado cuenta del funcionamiento de los medios de comunicación en los años de la dictadura cívico-militar en Argentina (1976-1983), los que se transformaron en un terreno de disputa y de tensión en lo político e institucional (Rodríguez, 2015; Schenquer, 2019). Estos enfrentaron situaciones financieras dispares, vejaciones de todo tipo ejercidas de forma directa a los empresarios y profesionales que se desempeñaban en estas actividades y decisiones inéditas en lo que atañe a las libertades creativas y de expresión (Getino, 2005; Romano, 2007). En el campo específico de la televisión, la política llevada a cabo por el poder militar estuvo signada por un rígido dominio y control estatal sobre la producción y la circulación de los mensajes (Varela, 2016; Heram, 2009; Califano, 2014). Dependientes del Estado desde 1974, la Junta Militar que asumió el 24 de marzo de 1976 decidió repartir el control de las emisoras nacionales y provinciales entre las nuevas fuerzas gobernantes, diseñando con estas directivas una red comunicacional de amplio alcance territorial. ${ }^{1}$

Convencidas de la potencia ideológica y comercial del medio, las autoridades propiciaron numerosas inversiones y proyectos modernizadores en infraestructura y tecnología. ${ }^{2}$ En el plano de los contenidos, si como expresa Pablo Sirvén la vigilancia y la censura implicó que "los noticieros y la intensa propaganda oficial se convirtieron en lo mismo y las crecientes y difusas listas negras dejaron fuera del medio a talentosas figuras y libretistas" (1998, p. 97), bajo determinadas circunstancias, los canales plasmaron piezas televisivas que escaparon, en alguna medida, al canon discursivo oficial y a las actitudes constrictoras de las autoridades. El creciente presupuesto concedido a las emisoras, la competencia que se estableció entre los canales por ganar y liderar las audiencias, "el mandato de reducir progresivamente la emisión de origen extranjero, en franca alusión a la cantidad de series y filmes que rondan generalmente las 48 horas del fin de semana” (Ulanovsky, Itkin y Sirvén,
2006, p. 397), las ambiciones de algunas de las máximas autoridades en el poder y las transiciones políticas que se vivieron en el período fueron factores que intervinieron en la renovación de las programaciones. Entre otras posibilidades, estas comenzaron a abarcar piezas ficcionales que obtuvieron amplia respuesta del público, entre las que cobraron impulso las telenovelas y los ciclos de ficción que estimularon visiones que confirmaban o cuestionaban la realidad argentina del momento.

Con el propósito de avanzar en el conocimiento de los enclaves de disidencia que se conformaron en el campo televisivo, y de reforzar la hipótesis de la existencia de un entramado cultural de discusión y de denuncia extendido en el que colaboraron estratégicamente profesionales y artistas de diferentes extracciones y disciplinas, ${ }^{3}$ el objetivo de este trabajo es analizar los ciclos de ficción con

1:: Canal 9 fue otorgado al Ejército, Canal 11 a la Fuerza Aérea, Canal 13 a la Armada. El Canal 2 fue intervenido por el Gobierno de la Provincia de Buenos Aires. ATC fue asignado a la Presidencia de la Nación. En 1981, con la crisis del poder militar, se puso en vigencia el Plan Nacional de Radiodifusión que se proponía la adjudicación de las licencias estatizadas al sector privado.

2:: Entre esos se destacan la inauguración en 1978 del complejo audiovisual Argentina 78 Televisora / Centro de Producción Buenos Aires, ideado para transmitir los partidos del Mundial de Fútbol de ese año; la creación en 1979, tras la fusión con el complejo audiovisual, de Argentina Televisora Color (ATC) -ex Canal 7- y el inicio de las transmisiones en color inauguradas el 1 de mayo de 1980.

3:: Los medios gráficos construyeron sus alternativas desde el humor y la sátira (Humor registrado), la cultura rock (El Expreso Imaginario) 0 investigaciones profundas y denuncias (El Porteño). En el espacio radial, las voces disidentes fueron escasas: el programa Anticipos de radio Continental fue uno de los pocos programas de oposición. El cine postuló algunas respuestas, con el ejercicio del documental de corte político-militante realizado en el exilio político (Campo, 2017) o bien con estructuras hermético-metafóricas, en una amplia serie de ficciones con financiamiento privado o estatal (Lusnich, 2019). La televisión del período fue un espacio blindado por el poder militar. Entre 1982 y 1983, Semanario insólito (ATC) fue uno de los pocos programas disruptivos. 
formato de episodios unitarios emitidos en la televisión de la época, que se caracterizaron por ejercer la crítica y la resistencia al régimen. Con el antecedente del exitoso ciclo Cosa juzgada (Canal 11, 1969-1971) -en pantalla en los años de la dictadura encabezada por Juan Carlos Onganía, Marcelo Levingston y Alejandro Agustín Lanusse $^{4}-$, este formato se reactivó y potenció durante el gobierno militar subsiguiente congregando la atención de vastos sectores de público. De acuerdo con el relevamiento realizado para esta ocasión, los ciclos televisivos de ficción estudiados son posteriores a 1979 y su realización se incrementó luego de 1981.

Si bien los lineamientos político-ideológicos del régimen no variaron completamente en todo el período, los historiadores coinciden en plantear tres fases internas que marcaron las fortalezas y el progresivo debilitamiento del proyecto político de la dictadura y de su discurso monolítico, derrotero en el que se inscribe el crecimiento de los ciclos televisivos abordados. Bajo esta perspectiva, entre 1976 y 1979 primaron las mayores coacciones a la ciudanía, imponiéndose el terrorismo de Estado con su maquinaria de tortura, muerte y desapariciones; de 1979 a 1981 se vislumbraron confrontaciones entre los diferentes sectores del cuerpo militar, las que incluyeron posiciones cruzadas (radicales, moderadas, presidencialistas) entre las principales autoridades y sectores; luego de la derrota en la Guerra de Malvinas en 1981, se reabrió el horizonte político local que culminó con la recuperación de la democracia en 1983 (Quiroga, 2004).

De acuerdo con las dinámicas televisivas de la época, los ciclos de ficción analizados fueron producidos y emitidos por tres de los cinco canales de mayor alcance nacional: ATC fue precursor en la reposición del formato en 1979 y el máximo promotor; Canal 9 lo secundó desde 1982; Canal 13 reafirmó la tendencia en 1983. ATC optó -con el ejercicio de Carlos Montero en la dirección artística del canal entre mayo y diciembre de 1979- por una programación que equilibró las perspectivas comerciales y culturales. Con trayectoria previa en Canal 13, Montero "logra negociar con el interventor una presencia mínima de programas proselitistas vinculados a los intereses de cada una de las Fuerzas Armadas que quedan limitados a la franja horaria que comenzaba a las 23 horas" (Sticotti, 2017 , p. 168). Luego de las desavenencias y del quiebre de las relaciones con el interventor, coronel Enrique Santos Paredero, el canal mantuvo su espacio de liderazgo, encabezando los índices de audiencia y obteniendo importantes réditos económicos.

Reafirmando las ideas de Montero, la planificación de la programación se sostuvo en dos líneas principales: la diversificación de la grilla -informativos, programas de humor, de actualidad, deportivos, musicales y ficciones-y la contratación de destacadas figuras del ambiente artístico. ${ }^{5} \mathrm{Su}$ más cercano competidor en la época, Canal 13, con el control de la Armada y la presencia de Emilio Eduardo Massera -integrante de la Junta Militar con aspiraciones presidencialistas-, propició de igual manera innovaciones tecnológicas en el plano del color con el sistema PAL-N adoptado en el país y la renovación de su equipo de cámaras y circuitos de transmisión. Teniendo un presupuesto más acotado, su programación no desestimó la contratación de intérpretes centrales en la época -muchos de los cuales serían protagonistas en los ciclos analizados- o la creación de telecomedias populares. ${ }^{6}$

4:: El ciclo tuvo dirección general de David Stivel, y Juan Carlos Gené fue el autor de la mayoría de los episodios. Los unitarios estaban basados en casos policiales y judiciales reales extraídos de los archivos de la justicia argentina. Amenazados -Stivel por la Alianza Anticomunista Argentina (AAA) y Gené por las autoridades militares que asumieron en 1976- se exiliaron en Colombia y en Venezuela, respectivamente.

5:: Apuestas fuertes de la emisora fueron el programa Almorzando con Mirtha Legrand, las telenovelas Andrea Celeste y Los hijos de López, y el noticiero 60 minutos.

6:: De Canal 9 no se conocen detalles específicos sobre su administración y postura artístico-empresarial; sí se puede aportar que, a excepción de las otras emisoras, su licenciatario previo al Golpe de 1976 mantuvo el litigio legal y recuperó la emisora recién en 1983. 
Partiendo de una selección de los unitarios que integraron los ciclos Los especiales de ATC (ATC, 19791983), Nosotros y los miedos (Canal 9, 1982 y 1983), Los siete pecados capitales (ATC, 1982), Compromiso (Canal 13, temporada 1983) y Situación límite (ATC, temporada 1983), ${ }^{7}$ se analizarán tres aspectos que, desde nuestro punto de vista, confluyeron en la demarcación de un fenómeno televisivo diferencial que trazó una distancia considerable con la producción hegemónica del período. Se consolidó así un espacio en el que la crítica y la resistencia al régimen militar se plasmaron de forma consistente, tanto en el plano textual como en el ámbito de la producción y de la recepción. En primer lugar, se abordará la constitución de un tejido artístico-creativo que obró proactivamente en la concreción de los ciclos. En segundo lugar, se estudiarán las características textuales de estos programas y su apuesta por modalidades narrativas y espectaculares que facilitaban, en un contexto de vigilancia y censura, abordar críticamente problemáticas relacionadas al presente histórico de la Argentina. Por último, se indagará en la producción de sentido, en la cual el "efecto de corpus" y la recepción cómplice de los espectadores adquirieron vital protagonismo.

Un tejido artístico-creativo en busca de la calidad, la solidaridad y la pluralidad

En sus formas de producción y características textuales, los ciclos que nos ocupan oscilan entre lo propiamente internacional y lo doméstico-nacional. En líneas generales se trata de programas que se ajustan a los patrones impuestos a nivel internacional: capítulos de trama cerrada, contenidos cimentados en lo dramático, personajes corales, duración media de 60 minutos, periodicidad semanal, emisión en la franja primer time, audiencia adulta (Saló, 2003; Carrasco Campos, 2010). No obstante, las prácticas y tradiciones locales imprimieron a estos programas una fisonomía propia relacionada con una serie de variables artístico-creativas que se sostuvieron en la reafirmación de la calidad de las emisiones, la facultad de la experimentación y el ejercicio de la reflexión y la crítica de la realidad (Ulanovsky, Itkin y Sirvén, 2006).

Una de las particularidades que responde a los usos y costumbres de la televisión argentina con respecto a estos ciclos ha sido la conformación de equipos creativos-artísticos sustentados en la cooperación de diferentes disciplinas artísticas y campos de acción, así como la convocatoria -en los rubros de la autoría, dirección, puesta en escena e interpretación- de profesionales con máximo reconocimiento en el campo cultural nacional. Si estas determinaciones repercutian en la calidad de las piezas realizadas y en la consecuente aceptación de las audiencias, en los años de la dictadura cívico-militar implantada en 1976 dejaron entrever otra arista relacionada con la conformación de lazos de solidaridad al interior de los canales, entre los civiles que en ellos trabajaban, o bien entre todos estos y segmentos de espectadores ávidos de escuchar voces alternativas a las hegemónicas.

En el primero de los ciclos puesto en pantalla en dictadura, Los especiales de ATC, se advierte el predominio de un sistema organizativo que oscila entre la rotación y la repetición de profesionales y artistas, lo que incidió en la posibilidad de amalgamar diferentes voluntades al interior de la emisora a fines de ser aceptado el proyecto. Fue también una táctica que dio oportunidades laborales a quienes estaban observados por el régimen

7:: Hasta la fecha no existe una catalogación completa de estos ciclos ni un resguardo material, situación que se condice con las deficitarias políticas archivisticas y de preservación de la producción televisiva del período. Elina Adduci Spina, catalogadora e investigadora del Archivo Histórico de Radio y Televisión Argentina (RTA), se encuentra desarrollando un proyecto de puesta en valor que incluye la digitalización, la catalogación y el estudio crítico del ciclo Los especiales de ATC y Situación límite. De los otros ciclos solo se han encontrado unitarios aislados en diferentes sitios de Internet. 
sin exponerlos de forma directa. Esto se hizo perceptible en el campo de la autoría ${ }^{8}$ y también fue una estrategia extendida en la conformación de los elencos, con la mixtura de intérpretes de probada e indiscutida trayectoria -en el medio teatral y cinematográfico- con actrices y actores de generaciones más jóvenes que tenían diferentes posturas políticas. Los otros programas estudiados, ya sea propios de ATC o los emitidos por Canal 9 y Canal 13 en los años subsiguientes, cimientan esta estrategia rotativa de los elencos contratando para sus unitarios al mismo grupo de actores. Este accionar colaboró en el sostenimiento económico de los intérpretes, más allá de fomentar la posibilidad de instituir un perfil artístico e ideológico plural. ${ }^{9}$

Mayor reincidencia de profesionales se advierte en las áreas de la dirección y de la puesta en escena, probablemente por recaer en estas las directrices estético-ideológicas de los ciclos. Si para el caso de Los especiales de ATC el protagonismo estuvo depositado en un conjunto de profesionales en particular-Héctor Flores, Nicolás del Boca y Eduardo Ocana en la dirección; Fernando Heredia y José María Paolantonio en la puesta en escena-, en el denominado Los siete pecados capitales (1982) la dirección fue contraída exclusivamente por Héctor Flores, unificándose en su persona las responsabilidades y los intercambios con la dirección artística de ATC.

Similar esquema prevaleció en los otros ciclos analizados: Rodolfo Hoppe estuvo a cargo de la dirección de los episodios de Compromiso (Canal 13), Alejandro Doria fue el director general de varias temporadas de Situación limite (ATC) y Diana Álvarez fue artífice de la idea general, la producción y la dirección de Nosotros $y$ los miedos (Canal 9). Sobre este último ciclo es de interés destacar, a través de la figura de Diana Álvarez, la opción por trazar un perfil profesional múltiple, que conciliaba la producción comercial destinada a audiencias populares -en este mismo período dirigió Un mundo de veinte asientos (1978) y El Rafa (1981) - con otra de sesgo decididamente cultural. Con la realización de Nosotros $y$ los miedos y con su posterior participación en la dirección de Nunca Más (1984) para la Comisión Nacional sobre la Desaparición de Personas (CONADEP), Álvarez incursionaba en el terreno de la reflexión y de la denuncia, articulando en cada una de estas, acorde con los tiempos políticos, formas de representación más o menos directas, que no evitaron sin embargo discusiones al interior de los espacios laborales. ${ }^{10}$

Con estos sistemas de organización y participación, las férreas directrices trazadas por las autoridades militares a los profesionales actuantes en los canales escaparon parcialmente a los designios ideológicos del régimen y auguraron una serie de intersticios y de vasos comunicantes en los que primaron los lazos sociales y la fraternidad. En tanto, por sus trayectorias artísticas, los profesionales y artistas congregados en estos programas aseguraban la realización de productos de buena factura técnica y expresiva, siendo igualmente rendidores desde el punto de vista comercial, ya que los unitarios se entretejían con avisos publicitarios que dejaban réditos económicos importantes a las emisoras.

8:: Autores clásicos de diferentes nacionalidades, textualidades y extracciones ideológicas (William Shakespeare, Pierre Wolff, Vladimiro Cajoli, Adolfo Bioy Casares, Enrique Santos Discépolo, Eduardo Mallea) convivieron con escritores y dramaturgos disidentes del régimen militar o, incluso, prohibidos y exiliados en el período (Aída Bortnik, Jacobo Langsner).

9:: Bajo este prisma, Mecha Ortiz, Luisa Vehil, Juana Hidalgo, Osvaldo Terranova -figuras centrales del campo artístico local-compartieron cartel con otras más jóvenes de reconocimiento popular -Andrea del Boca, Ricardo Darín-. Quienes cuestionaban al régimen militar -Maria Leal, Marta Bianchi, Ulises Dumont, Héctor Bidonde-, incluso quienes estuvieron en las listas negras de personalidades observadas y prohibidas por la dictadura -Marta Bianchi, por ejemplo- también tuvieron espacio en los unitarios de este ciclo.

10:: En una nota del diario La Nación se reproduce una declaración de Diana Álvarez en la que esta detalla algunos pormenores sobre el ciclo: "en el programa pusimos todo y tuvimos una lucha fuertísima con los militares y con el canal. Y lo hicimos por la prensa. Si la prensa no lo hubiera apoyado desde el principio no habriamos podido continuar" (citado en "Murió Diana Álvarez", 2018). 
Experimentación y búsquedas en favor de la crítica y la resistencia al régimen

El segundo aspecto distintivo de los ciclos aquí explorados es haber generado espacios de experimentación, especialmente en el orden de lo interdisciplinar. Si bien esta tendencia no fue exclusiva del país, ${ }^{11}$ sin dudas no se convirtió en una marca singular ni perdurable a nivel global. En lo que corresponde a las relaciones entre el teatro y la televisión en Argentina, Mirta Varela (2005) sitúa en la segunda mitad de la década del 60 un punto de inflexión radical que desarticula las convenciones del teatro televisado y de las adaptaciones especiales para televisión, a favor de una síntesis intermedial superadora. Esta no solo lleva a olvidar viejas rivalidades -como aquellas que contraponían la profesionalización y la maduración del estilo del teatro al oficio y la superficialidad de la televisión-, sino a su vez a actuar conjuntamente en el terreno de la experimentación y la renovación estética.

Por la forma en que se insertan en las grillas, el éxito logrado en las audiencias, la irreverencia de las puestas en escena, la innovación en los mecanismos textuales y la conformación de elencos estelares, los hitos de la época ${ }^{12}$ ponen de manifiesto una nueva "sincronía entre el teatro y la televisión (...) que intentó mostrar una versión bien contemporánea" del panorama artístico-cultural (Varela, 2005, p.190). En consonancia con estas ideas, en su estudio de las transformaciones del paradigma artístico local en los años sesenta, Jorge Sala (2019) identifica la toma de posición estético-ideológica y las estrategias de asociación puestas en marcha de forma conjunta por los sectores emergentes en el campo del cine y del teatro. En la mención de las principales direcciones afrontadas por los nuevos agentes artísticos, Sala destaca la "consolidación de un circuito común de espectáculos y las propuestas interdisciplinares" (2019, p. 218), entre las que se incluyen sin lugar a duda las impulsadas por el medio televisivo de entonces, abierto a renovar sus estructuras textuales y estéticas, e incluso a funcionar como un espacio germinal de obras teatrales y cinematográficas. ${ }^{13}$
Si nos atenemos a los años de la última dictadura cívico-militar, las ansias de experimentación y los diálogos interdisciplinares se tramaron al interior de los ciclos de ficción estudiados. Estos proyectaron aquella oleada modernizadora que en los años sesenta dominó el campo cultural y artístico con gran audacia. Por otra parte, tres prácticas estético-creativas detectadas en las piezas estimularon la búsqueda de modalidades de expresión que potenciaron en diferentes niveles -narrativo, discursivo y de puesta en escena- el ejercicio de la crítica y la resistencia al poder dictatorial. ${ }^{14}$

De acuerdo con las características intrínsecas de los episodios unitarios de ficción enumeradas por Ángel Carrasco Campos (2010) -costos altos, inversión de los canales, mayor tiempo de producción, guiones más trabajados que permiten ahondar en la construcción de los

11:: Gran Bretaña y Estados Unidos imprimieron en sus grillas televisivas de las primeras décadas la afición por el teatro filmado y por la producción televisiva interdisciplinar con fuerte injerencia del medio teatral.

12:: La versión de Hamlet, dirigida por David Stivel y protagonizada por Alfredo Alcón (Canal 13, 1964), compuso una puesta en escena singular y actualizada a las coyunturas políticas de los años 60 . Entre las novedades, los personajes portaban ametralladoras y pistolas, en una clara referencia a la escalada de violencia que se vivía en el país y en el mundo. El ciclo Cosa juzgada, por su parte, no se basó en la adaptación ni en la imbricación tradicional entre teatro y televisión, sino que "se orientó a la exploración entre ficción y realidad" (Varela, 2005, p. 192).

13:: Ricardo Halac (1998), dramaturgo y escritor de libretos y adaptaciones para la televisión, destaca cómo los unitarios de televisión dieron origen a filmes y textos dramáticos de gran trascendencia en la cultura argentina.

14:: Los unitarios digitalizados o conservados materialmente localizados para este artículo son de 1981, 1982 y 1983. De estos se realiza un análisis textual más profundo; sobre los restantes, los medios gráficos de la época, la bibliografía especializada y algunas catalogaciones producidas en torno a algunas figuras que han intervenido en ellos, aportan información sobre los procesos de producción, creación y recepción. 
personajes, cuidados en los rubros técnicos-, los equipos de trabajo refrendaron los procesos de creación complejos, focalizados en la preparación y la discusión de los libros tanto como en los ensayos con los intérpretes. Con estas decisiones alimentaron la posibilidad de ahondar en problemáticas acuciantes, con énfasis en lo actoral, ${ }^{15}$ y también estimularon la creatividad en el diseño de puestas en escena que reforzaban los conflictos, con la participación comprometida de los directores artísticos, los escenógrafos y los iluminadores.

Bajo estas orientaciones, en el marco de Los especiales de ATC se destaca el programa emitido el 4 de junio de 1982, que tenía como protagonista a Susana Rinaldi. Compuesto en el formato del unitario musical con entrevistas e invitados especiales, la directora general del ciclo María Herminia Avellaneda ideó una serie de modificaciones estético-creativas novedosas que combinaron la reformulación del esquema convencional del musical con el comentario crítico-reflexivo sobre el estado de cosas imperante en la época. Con estos propósitos, alternó números musicales grabados en los estudios de ATC y en exteriores, siendo un patrón la cuidada puesta de cámara y de luces en pos de un atractivo producto audiovisual. De igual forma, si el unitario se encontraba atravesado principalmente por el tango con la presencia de indiscutidas figuras (Eladia Blázquez, Horacio Ferrer, Amelita Baltar) y la recreación estilizada de algunas locaciones emblemáticas de su universo (los pasajes del barrio de San Telmo, el interior de un café), resulta de interés mencionar la inclusión de varios temas compuestos por María Elena Walsh, Antonio Tarragó Ros y Chabuca Granda, ${ }^{16}$ todos ellos interpretados por Susana Rinaldi.

El unitario mutaba así de una estructura musical tradicional y cerrada, en favor del diálogo entre diferentes géneros musicales y cancioneros, situación a la que se sumaba la puesta en escena ficcionalizada de los números musicales. En tanto, la decisión de Susana Rinaldi -y de la producción general del unitario- de seleccionar e interpretar temas de artistas censurados u observados en la dictadura implicaba una actitud de resistencia por dar voz a quienes el poder político había silenciado y por develar el cercenamiento de la libertad de expresión implementada de forma extendida en el campo artístico y cultural.

Situación límite, puesto en el aire en 1983 en coincidencia con el tramo final del proceso electoral que daría fin al gobierno de facto, intensificó estas búsquedas en el nivel de lo dramático-interpretativo al incorporar las técnicas del psicodrama al campo de la televisión. Habiendo sido muy efectivo en el espacio del teatro argentino, con el impulso de Eduardo Pavlovsky, el psicodrama aplicado al campo artístico reelaboraba las formas de la psicoterapia grupal, exponiendo los vínculos de opresión y alienación mediante los recursos del encuentro personal, las acciones verbales y físicas y la implementación de la improvisación (Kesselan y Pavlosvsky, 1989).

Con producción de Jacinto Pérez Heredia, dirección de Alejandro Doria (temporadas 1983-1984) y guiones de Nelly Fernández Tiscornia, los unitarios que componían Situación limite adecuaron estos parámetros

15:: Testimonio de estas prácticas - uno de los pocos que se preservan- es la grabación de los encuentros de discusión realizados para la confección del unitario Miedo al presente. Aprender de nuevo (Nosotros y los miedos), probablemente emitido en 1982. En el fragmento, se ve que un hábito compartido por el teatro y la TV en la época era la reunión de los intérpretes alrededor de una mesa (en este caso en un bar), el diálogo y la confrontación de ideas en torno al "miedo" de cada semana. Así, los intérpretes vertían sus puntos de vista - disímiles, plurales-y luego el director postulaba las perspectivas finales que adoptaría el unitario ("Los miedos del pasado", 2009).

16:: El 16 de agosto de 1979, el diario Clarín publicó el ensayo "Desventuras en el País Jardín-de-Infantes", firmado por Maria Elena Walsh donde realizaba una fuerte denuncia contra la dictadura. Su obra fue inmediatamente censurada y sus actuaciones prohibidas. Tarragó Ros fue uno de los integrantes de la Nueva Trova Correntina que hacia mediados de los 70 transformó el chamamé con melodías musicalmente complejas y letras comprometidas con la realidad. Maria Isabel Granda y Larco (Chabuca Granda), letrista, cantautora y folclorista peruana, se volcó a la canción social en los 69 y 70, lo que despertó sospechas en las autoridades militares locales. 
de forma creativa. Se concentraban en los encuentros personales extensos y extremos que se tejían, en paralelo, pero con algún punto de cruce, entre dos parejas de intérpretes que exponían conflictos de raigambre familiar y social. La puesta en escena minimalista y la iluminación basada en el contraste potenciaban el conflicto intimista y la contienda verbal: el fondo era neutro y oscuro, los intérpretes portaban vestuarios claros, los escasos objetos escenográficos se encontraban intensamente iluminados. El empleo de primeros planos, la profundidad de campo y los movimientos de cámara envolventes funcionaban como refuerzos expresivos de las situaciones, de los momentos de clímax y anticlímax dramáticos.

Dos emisiones de este ciclo -los denominados Por qué? y El choque- ponen en evidencia la productividad de estas técnicas en los planos expresivo y semántico, retomando de forma crítica y reflexiva problemáticas que se ajustaban a la realidad política y social vivida en la dictadura. Ambos se estructuran en torno a un leitmotiv (la pregunta “¿por qué?” en el primero, la palabra "justicia" en el segundo) que, de acuerdo con la confrontación de los personajes y la exposición de diferentes puntos de vista, ve modificado o amplificado su sentido en el curso del programa. Por qué? afronta el tema de los desaparecidos en dictadura, contraponiendo diferentes posiciones y grados de reflexividad de parte de los protagonistas: frente a la ignorancia y los prejuicios de su esposa - esta difama y califica de inmoral a una vecina que vive sola con su hijo-, el marido aporta conocimiento de la situación y empatía revelando a su esposa la condición de detenido-desaparecido del hombre ausente. En el hogar vecino, el hijo del padre desaparecido interpela a su madre en búsqueda de respuestas. Con estos trayectos dramáticos, el interrogante que da nombre al episodio se reformula en dos direcciones diferentes: una apunta a develar y a cuestionar la tendencia a la sospecha y a la desaprensión social reinante en esos años; la segunda recae en el desconsuelo de una mujer que ha perdido definitivamente a su esposo y no encuentra explicaciones a lo sucedido. ${ }^{17}$

El choque, por su parte, versa sobre el ejercicio del poder, la confrontación de clases sociales y la necesidad de justicia. En uno de los núcleos familiares, una pareja aristócrata y de muy buen pasar económico discute la renuncia del marido a la jefatura de un movimiento político que a lo largo del tiempo ha dado apoyo a los gobiernos conservadores, incluidos los de facto ${ }^{18}$ Ante la actitud reflexiva y decidida del hombre, la mujer expone su negativa a la pérdida del poder y del estatus social a los que está acostumbrada. Simultáneamente, otra pareja descubre la militancia juvenil de su hijo, la que es aceptada por su madre y cuestionada por el padre. Sin embargo, los motivos de lucha de su hijo -la denuncia de un profesor que manosea a los estudiantes-, junto con el recuerdo de situaciones dolorosas del pasado -la madre rememora los abusos de un patrón-y del presente -el padre logra contar un hecho cotidiano vivido ese mismo día, que consistió en la embestida del auto de la familia aristócrata a su camioneta y ante la cual se sometió por temor-, determinan la toma de conciencia de la pareja y el consecuente pedido colectivo de justicia. Como es posible apreciar, en estos dos unitarios las técnicas del psicodrama -en particular las confrontaciones verbales y el fluir y la circulación de las palabras y del saber-, se encuentran íntimamente relacionados con la capacidad de hacer aflorar situaciones hasta entonces no dichas o difíciles de afrontar, el recuerdo, la memoria y la búsqueda de algún tipo de entendimiento.

En tercer lugar, la mayoría de los ciclos y unitarios analizados han coincidido en reinterpretar las

17:: Si bien la palabra "desaparecido" no se menciona, se alude a esta circunstancia ya conocida públicamente en 1983. El vecino dice que la mujer tiene un marido que no se sabe dónde está o si está; el hijo del hombre ausente pregunta si su padre se fue, está preso o muerto.

18:: Esto lo da a entender un dicho del hombre, quien sostiene haber participado de la puesta en marcha "de un aparato para hacer callar". 
tendencias del realismo reflexivo y de la neovanguardia emergentes en la década del 60 en el campo teatral porteño (Pellettieri, 2001a), ${ }^{19}$ compartiendo estas directrices con las experiencias teatrales y cinematográficas contemporáneas que se aferraban a las modalidades de representación que, evadiendo el canon realista-mimético, permitían tematizar y representar audiovisualmente los núcleos críticos y cuestionables de la realidad argentina del período. ${ }^{20}$

Como ejemplo de las correspondencias trazadas entre los unitarios que componen los diferentes ciclos, El atajo (emisión doble), Proceso a cuatro monjas (emisión doble) -Los especiales de ATC- y El espejo (Miedo a ver) -Nosotros y los miedos- sostienen numerosas coincidencias en sus problemáticas y determinaciones estéticas. Amalgamando postulados de las dos tendencias mencionadas, las características más destacadas son: el diseño de estructuras dramático-narrativas que se sostienen en el desenmascaramiento de historias o de sucesos ocultos que, al develarse, provocan la desarticulación de la vida cotidiana de los personajes y el quiebre de sus identidades; el aislamiento de los personajes protagónicos en espacios cerrados y claustrofóbicos de alto contenido simbólico; la presencia dramática de una extraescena antirrealista, y las clausuras abiertas que establecen un horizonte de incertidumbre y de inestabilidad emocional radical en los sujetos dramáticos.

En El atajo, Ambrosio Guzmán y Rubén Batistella, vecinos en un complejo de viviendas de la Provincia de Buenos Aires, comparten un viaje en auto. Tras un desperfecto mecánico, son acogidos en un misterioso edificio abandonado en el que tienen encerrados a numerosos hombres. Inmersos en un tiempo y espacio ambiguo, en un universo intrigante y surreal, el relato de Adolfo Bioy Casares publicado en su libro Historias Fantásticas (1972) se actualiza en este unitario en función de los datos del presente histórico, personal y social. Los secretos que salen a la luz (la infidelidad de la esposa de Guzmán con Batistella, la incertidumbre sobre la verdadera identidad del hijo de Guzmán) transfiguran la vida cotidiana de los personajes para siempre. Luego de la revelación, en la segunda parte del unitario Guzmán retorna a su casa con el propósito retomar su vida familiar; sin embargo, la noticia del asesinato de Batistella subvierte sus intenciones y desata una crisis en su mujer. ${ }^{21}$

Como expusimos, el barrio popular y la carretera son suplantados transitoriamente por un entorno antirrealista, en el cual los códigos de la puesta en escena y la interpretación de los personajes remiten a conductas y a prácticas relacionadas con el encierro y la tortura. En ese

19:: El realismo reflexivo entabla una relación directa con el referente, representa e interpreta los hechos cotidianos, produce un mensaje y una tesis sobre la realidad. En tanto, la neovanguardia forja una relación opaca, cuyas marcas y operatorias en textos y puestas en escena son la expresividad, la inconexión, la deformación y el extrañamiento. A raíz de una polémica en aquel momento (Pellettieri, 2001b), los partidarios del realismo reflexivo acusaban a los neovanguaristas de apolíticos y de no estar comprometidos con su tiempo. Con el paso de los años, ambos limaron asperezas; en dictadura, ambos se opusieron al régimen.

20:: Teatro Abierto 1981, primera edición del ciclo, se realizó en agosto y septiembre de 1981 en el Teatro del Picadero y en el Tabarís. En ese espacio compartieron escenario las realistas reflexivas Lejana tierra prometida (Ricardo Halac), Gris de ausencia (Roberto Cossa), El acompañamiento (Carlos Gorostiza) con las neovanguardistas Decir sí (Griselda Gambaro), Tercero incluido (Eduardo Pavlovsky), Mi obelisco y yo (Osvaldo Dragún). En artículos previos (Lusnich 2016, 2019) se analizaron las características textuales de los filmes realizados en dictadura, denominados "hermético-metafóricos". La construcción de relatos que evadian la representación realista-mimética y la preeminencia de las operaciones alegóricas y metafóricas en el plano de la narración, el sistema de los personajes y la puesta en escena, fueron las características textuales que dieron singularidad a la tendencia.

21:: De acuerdo con el relato del hijo de Guzmán, Batistella aparece tendido en la ruta con un tiro en la cabeza y mutilado por unos perros. Las claves narrativas y representacionales ancladas en la ambigüedad (no todo se dice o se ve), dejan dudas sobre los verdaderos autores del asesinato, pudiéndose adjudicar a los captores de los dos hombres o bien al propio Guzmán. Sugestivamente, remarcando esta dualidad, al llegar a su casa Guzmán saca de su bolsillo uno de los guantes utilizados por los secuestradores en su rutina diaria, en tanto también porta un arma. 
"otro espacio", ya sea por los datos expuestos directamente en las escenas -médicos y enfermeras interrogan, hostigan y torturan a quienes encierran - o bien indirectamente a través de la extraescena -puertas entreabiertas dejan ver hombres amontonados, en estado crítico, balbuceando frases incomprensibles; la profundidad sonora arroja quejidos y gritos de personas; motivos sonoros extradiegéticos construyen climas inquietantes-, se teje una relación indirecta aunque significativa con el presente dictatorial de la Argentina, produciéndose sentidos connotados que exceden la historia de Guzmán y Batistella. ${ }^{22}$

Proceso a cuatro monjas parte de un relato situado en Europa en el ocaso del nazismo, momento en el que cuatro mujeres perseguidas por sus vínculos con el ejército alemán deciden apropiarse de las identidades de cuatro monjas fallecidas, protegiéndose del mundo exterior en un claustro monástico. ${ }^{23} \mathrm{Al}$ revelarse el fraude, las autoridades inician un proceso judicial en el que conviven las intrigas políticas y los prejuicios sociales (las mujeres presuntamente han servido sexualmente a los alemanes). Por tratarse de piezas construidas sobre el subtexto, las problemáticas de la persecución, el encierro, la difamación y la usurpación de las identidades aluden transversalmente a la realidad vivida en los años del gobierno de facto, en tanto se trataba de núcleos conflictivos implícitos, en torno a los cuales una parte importante de la población argentina tenía información previa, y otra la adquiría con estas propuestas culturales. De igual forma, comparativamente, los espacios de clausura -representados por el monasterio en este unitario y por el edificio abandonado en El atajo- pueden interpretarse en sintonía con la opción del exilio interior -en tanto exclusión vivida por voluntad o por necesidad, para preservar la vida frente a una amenaza real- o bien con los espacios de encierro y cautiverio de los opositores políticos puestos en práctica por las autoridades militares.

En lo que respecta a El espejo (Miedo a ver), en plena coincidencia con El atajo, se plantea la estrategia de la cesación del tiempo y del espacio cotidiano, familiar y social, centrándose en la historia de una mujer que, ciega desde niña y habiendo recuperado la vista de adulta, declina formar parte de un mundo que no comprende y que le disgusta. En esta oportunidad, la capacidad de ver-mirar-saber coloca a la mujer en una disyuntiva. De cara a la realidad -cuestiona los lazos familiares y sociales, la ausencia de empatía, el ejercicio de la violencia entre pares-, la mujer edifica en su espacio familiar una especie de casa-trampa, ya que este entorno pierde su antigua capacidad de refugio para dejarla completamente desamparada. ${ }^{24}$

22:: Los sentidos connotados se construyen en los diferentes niveles textuales. Algunos de ellos producen cierta idea de "extrañamiento" frente al mundo, como el guante que saca Guzmán de su bolsillo o el sangrado repentino, sin una explicación lógica, en una de las manos del personaje del trabajador en El choque. Otros son más transparentes y funcionan como comentarios narrativos de los productores y directores. Asi, dos situaciones presentes en los unitarios Por qué? (una mujer se saca el corpiño y su espalda desnuda queda a la vista de los espectadores) y El choque (un hombre se cambia el pantalón y deja ver su ropa interior) refieren a la censura sobre los cuerpos y la sexualidad impuesta en la dictadura, al menos en la televisión.

23:: Se trata de una adaptación de la obra original del italiano Vladimiro Cajoli. Nelly Fernández Tiscornia figuró como autora de la adaptación. Sin embargo, entre la documentación de archivo que dio origen a la investigación Las cajas de Aída: el catálogo, realizada sobre la producción de Aída Bortnik -autora exiliada en España entre 1976 y 1979-, se encontraron copias de los guiones de este ciclo, con anotaciones personales e indicaciones para los actores (Di Francesco, Fantl, Molina y Téramo, 2019).

24:: Estos unitarios guardan relación con piezas teatrales y filmes realizados en el período en sus vertientes más o menos realistas que abogan por los principios constructivos mencionados, lo que refuerza la idea de la existencia de un tejido textual y cultural interdisciplinar. Tercero incluido (Eduardo Pavlosvky), presentada en Teatro Abierto 1981, exacerbaba la situación de una pareja atrincherada en la habitación de su casa ante la espera de un ataque inminente. En su progresión dramática, la extraescena amenazante se traslada al interior de la habitación, transformando los encuentros de los personajes en vínculos crispados y violentos. La textualización en la narración y en la puesta en escena del enemigo invisible que determina la reclusión -o la huida del peligro- reaparece, de igual forma, en toda una amplia serie de filmes de esos años, entre ellos La isla y Los miedos (Alejandro Doria, 1979 y 1980). 
Producción de sentido, efecto de corpus y recepción cómplice

En lo concerniente a la producción de sentido, consideramos que esta se asienta mancomunadamente en las acciones de los profesionales y creadores que cooperaron en la realización de los ciclos, en el plano de lo material y en la participación atenta y cómplice de las audiencias (Verón, 1993; Pellettieri, 1994; Ferrés Prats, 2008). Sobre el primer aspecto, se observa que, en los intersticios gestados al interior del medio televisivo en un contexto de producción-realización adverso, los equipos de trabajo se reunieron y enfocaron en un tipo de creaciones con historia y tradición en la televisión argentina reforzando algunos de sus puntos nodales en función del contexto político-social. En estas acciones y comportamientos se ven procesos de cambio social orientados a la reflexión y a la crítica, con la toma de posiciones más o menos explícitas en torno al presente dictatorial. Diseminadas en los diferentes canales de aire, en prácticamente todo el período, asumimos que estas prácticas y directrices intervinieron en la conformaron de un espacio televisivo de disidencia y de resistencia al poder militar.

Si nos atenemos al plano de lo material, la producción de sentido se plasmó al interior de cada unitario y de cada ciclo, si bien también se trazaron relaciones medulares entre los ciclos de los diferentes canales, y de estos con otras experiencias y creaciones cinematográficas y teatrales. Con base en estas circunstancias, el "efecto de corpus” (Aumont, Bergala, Marie y Vernet, 2008) edificado por estos ciclos televisivos se caracterizó por su paulatina expansión y fortalecimiento, acorde con las propuestas estéticas e ideológicas de los episodios y ciclos, y el escalonado debacle de la dictadura.

En un primer orden de cosas, este efecto de corpus se hizo manifiesto en las denominaciones de los ciclos y de sus unitarios, los que designaron situaciones personales o grupales de antagonismo, disconformidad, temor y angustia; en tanto, en más de una ocasión, estos apelativos incluyeron pronunciamientos directos en torno a coyunturas políticas y sociales de la época sin que estos estuvieran reflejados con similar determinación en el desarrollo de los capítulos. ${ }^{25}$

Por otra parte, de acuerdo con las apuestas narrativas y de puesta en escena desglosadas en el apartado anterior, en su visión conjunta los ciclos elaboraron una textualización de la memoria histórica (Tarantuviez, 2007) asentada en una serie de problemáticas recurrentes que giraban en torno al abuso de poder, la injusticia, la crisis de la identidad, la presencia de un enemigo invisible y el miedo a vivir, entre las predominantes. ${ }^{26}$ La dificultad o incapacidad de asumir responsabilidades familiares y sociales - una de las vertientes aglutinadas en el tópico del miedo a vivir- tuvo representaciones divergentes, conforme con las perspectivas adoptadas por los creadores, y con la necesidad de promover visiones que pretendían reimplantar o estimular los valores de la reflexión o de la crítica en el seno de las producciones culturales. Como ejemplo, en 1983, uno de los ciclos revertía la tendencia del silenciamiento y el ostracismo, ya sea en su denominación tanto como en los conflictos que aborda: nos referimos al ciclo Compromiso y, en particular, al unitario

25:: Los títulos del ciclo y de cada unitario de Nosotros y los miedos son un claro exponente de estas operatorias. Entre ellos, Me quedo aquí, quieto (miedo al mundo), emitido en 1982, establece en su denominación un sentido connotado amplio que refiere al estado de ánimo de un sector de la población en los años de la dictadura, para luego acotarse en el desarrollo del episodio a la historia del personaje de Antonio, joven tímido que para comunicarse se desinhibe consumiendo alcohol.

26:: La crisis de la identidad dominó las historias de varios unitarios. Algunos abordaron la problemática de la adopción irregular de niños, lo que conllevaba a debatir la alteración de la identidad, en clara alusión a las informaciones y denuncias que se comenzaron a conocer en el período, vinculadas con la apropiación de niños de personas detenidas-desaparecidas. Son ejemplo los unitarios Quienes son mis padres (Los especiales de ATC) y La adopción (Compromiso, 1983). El primero desarrollaba las disputas sobre la tenencia de un niño entre dos parejas de adoptantes, con la complicación adicional del retorno y el reclamo de los padres biológicos. 
escrito por Ricardo Halac, Elegimos vivir. Por su parte, otros programas se enfocaron en las limitaciones de sus personajes; entre ellos, el unitario La pereza (1982) del ciclo Los siete pecados capitales- se centraba en la historia de Ivanna, reconocida escritora que se niega a intervenir en una serie de situaciones adversas que atraviesa el pueblo de Acequia Vieja, del cual había sido parte su familia.

La recepción atenta y cómplice generada en las audiencias del país - no hay que olvidar que los ciclos llegaban o se repetían en todo el territorio argentinoratifica su significación en el contexto de la época, siendo motivos de la aceptación y del seguimiento en el tiempo la pregnancia de los intérpretes y creadores convocados, pero también la producción de sentidos connotados. Si, como sostenía Ricardo Halac (1998), "artistas y públicos se encontraban en estos programas y pensaban juntos. Aunque los separaran miles de cables electrónicos", los espectadores generaron un estilo de recepción cómplice, ${ }^{27}$ una voluntad receptora que propiciaba la decodificación de la trama alegórica $\mathrm{y}$ metafórica inscripta en los unitarios y, consecuentemente, el reconocimiento de estos como piezas que ejercían la reflexión y la crítica política. Retomando a Joan Ferrés Prats (2008), a diferencia de otros programas, los ciclos televisivos aquí tratados dinamizaban los vínculos entre los productores-emisores, los textos y los receptores, suscitando una "experiencia transindividual" que ponía de manifiesto la inmersión de las personas en un espacio cultural en actividad, en el cual asumían protagonismo.

\section{Conclusiones}

A lo largo del artículo se exploraron las características intrínsecas de una serie de ciclos televisivos de ficción, en formato de episodios unitarios, realizados en los años de la última dictadura cívico-militar en Argentina, identificándolos como un espacio de crítica y de resistencia en el orden de lo político y de lo cultural por igual. En lo que respecta al volumen de la producción y la respuesta de los espectadores, pudimos constatar que se trató de un tipo de programa que se expandió en la televisión de la época, siendo los factores principales de su crecimiento el rédito económico que estos brindaban a los canales, pero de igual forma el entramado de acuerdos y de adhesiones forjado entre los creadores y vastos segmentos de espectadores. En el reconocimiento de estos ciclos, en pos de diferenciarlos de la oferta televisiva oficial del momento, acentuamos la articulación de dos hábitos o métodos asociados al ejercicio de la crítica y de la resistencia en diferentes niveles. A partir de estos núcleos, advertimos que los programas postulaban la exposición de problemáticas apremiantes e intimamente relacionadas con el abuso de poder de la dictadura -silenciadas, ocultas, naturalizadas, en palabras de Laura Schenquer (2919)-, su discernimiento y análisis, su enjuiciamiento y la búsqueda de otras prácticas y conductas.

La primera singularidad analizada se enfocó en los criterios de producción y de creación de los programas, territorio en el que pudimos identificar la prevalencia de los lazos sociales y fraternales gestados en los equipos de trabajo independientemente de la jerarquía y del grado de responsabilidad de sus integrantes. Observamos que estos se organizaron en torno a tres orientaciones que contemplaron las urgencias económicas de los profesionales y artistas - muchos de ellos distanciados de sus espacios habituales de trabajo por ser observados y/o perseguidos por el poder militar-, el impulso de obras de calidad y buena factura audiovisual y la decisión de ofrecer productos que adoptaran una distancia crítica y reflexiva con las directrices ideológicas y políticas instituidas.

27:: Al referirse al campo teatral argentino de los años 60 y 70, Osvaldo Pellettieri (1994) reconocía que en el momento en que los regímenes autoritarios se entrometen en el campo intelectual, las producciones culturales y artísticas acentúan la crítica oblicua al contexto social. De esta manera, las metáforas transparentes de la realidad permiten una recepción cómplice de un público avisado que participa de la crítica instaurada en los textos. 
En segundo lugar, advertimos las singularidades en el orden de las búsquedas estéticas, la experimentación y las relaciones sostenidas con otras disciplinas artísticas. En particular, se hizo hincapié en tres prácticas estético-creativas que potenciaban por igual los niveles narrativo, de puesta en escena, discursivo y semántico. Respecto de la transformación de los géneros televisivos tradicionales comprobamos que esto operó en el caso del musical, en uno de los unitarios del ciclo Los especiales de $A T C$, circunstancia que habilitó el cruce de géneros musicales y cancioneros. En esa oportunidad, la decisión de abrir el unitario con la canción "Como la cigarra", de María Elena Walsh, interpretada por la protagonista del programa Susana Rinaldi, compendiaba los lazos de solidaridad trazados entre los artistas y creadores; entretanto, la canción -grabada inicialmente en 1973adoptaba una significación particular, representando la voz de un sector social y político acallado en la Argentina (González Barroso, 2013).

En torno a la inclusión de la técnica del psicodrama, se observó que los procedimientos del encuentro personal -con sus enfrentamientos verbales, la confrontación de ideas y el trazado de personajes reflexivos- oscilaban entre el enfoque terapéutico y la resistencia al estado de cosas imperante, lo que necesariamente no implicaba el éxito de los personajes o la reversión de sus situaciones. ${ }^{28}$ Sobre la actualización de las modalidades del realismo reflexivo y la neovanguardia, quisimos expresar que su elección fue sumamente favorable para los ciclos y sus unitarios. Se trataba de tendencias que permitían la crítica al contexto social, en tanto los datos del presente histórico se hacían presentes en los diferentes niveles del texto audiovisual de forma oblicua o indirecta. Algunos de los procedimientos analizados (la suspensión del tiempo presente y cotidiano, la sumisión de los personajes en espacios cerrados, el extrañamiento frente a situaciones inesperadas, el valor de la extraescena) contribuyeron significativamente en la potencia expresiva de los unitarios tanto como en la constitución de sentidos connotados. Simultáneamente, por haber sido adoptadas ambas tendencias por un amplio arco de piezas teatrales y cinematográficas contemporáneas, interpretamos que todas estas disciplinas artísticas conformaron un tejido artístico-cultural que comulgaba los mismos intereses.

Por último, nos detuvimos en las relaciones trazadas entre los productores-creadores, las obras y las audiencias, siendo el magnetismo de los actores y de las actrices, los temas desplegados y la calidad de las emisiones tres aspectos centrales que acrecentaron la atención de los receptores. En cuanto a la relevancia política, social y cultural, consideramos que la trascendencia de esta propuesta televisiva estuvo asociada a la creación de un tipo de experiencia que contribuyó proactivamente -ya sea en lo que refiere a los productores-creadores como a las audiencias- en su identificación como sujetos sociales activos. Las emisiones apelaron a la participación afectiva y a la emoción, a la empatía, a la identificación, incluso gestionaron la capacidad de acción. ${ }^{29}$ Pero, sobre todo, estimularon los valores de la reflexión, el diálogo, la confrontación de ideas y la pluralidad de voces, parámetros por los cuales se distanciaban radicalmente del orden ideológico y social hegemónico.

28:: Los finales de los programas Por qué? y El choque indican versatilidad en lo que atañe a la reparación de situaciones adversas. En el primero, en la escena que cierra el unitario, la esposa del hombre desaparecido cuenta a su hijo una historia que rememora la trágica noche de su detención. Para la mujer, el recuerdo y la memoria asumen connotaciones positivas y negativas simultáneamente ya que, si por un lado permiten rememorar y retener la figura del padre, también hacen tomar conciencia sobre su ausencia irremediable. En El choque, en cambio, las conductas se modifican radicalmente, augurando la demanda colectiva de justicia que encamina una de las parejas la posibilidad de cambios en el plano político y social.

29:: Las miradas a cámara de los personajes y la ruptura de la cuarta pared fueron recursos muy utilizados en las emisiones, especialmente en la instancia de la clausura. Volviendo al ejemplo de El choque, estos procedimientos implicaban el contagio afectivo y activo de los espectadores, quienes se veían involucrados en un reclamo de justicia que se iniciaba en el núcleo familiar para ampliarse al ámbito social. 


\section{Referencias}

Aumont, J., Bergala, A., Marie, M., y Vernet, M. (2008). Estética del cine. Espacio fílmico, montaje, narración, lenguaje. Buenos Aires, Argentina: Paidós.

Califano, B. (2014). Hacia los orígenes de la concentración mediática en Argentina. Íconos. Revista de Ciencias Sociales, 49, 29-48.

Campo, J. (2017). Revolución y Democracia - El cine documental argentino del exilio 1976/1984. Buenos Aires, Argentina: Fundación CICCUS.

Carrasco Campos, Á. (2010). Teleseries: géneros y formatos. Ensayo de definiciones. Mhcj, 1, 174-200.

Di Francesco, S., Fantl, G., Molina, P. y Téramo, T. (2019). Las cajas de Aída: el catálogo. Buenos Aires, Argentina: Treintayseis. Recuperado de http://www.lascajasdeaida.com.ar/wp-content/ uploads/2020/02/LAS_CAJAS_DE_AIDA.pdf

Ferrés Prats, J. (2008). De la emoción por el consumo de emociones. Televisión, consumo y emociones. En I. Aguaded (Ed.), La otra mirada a la tele. Pistas para un consumo inteligente de la televisión (pp. 47-56). Madrid, España: Grupo Comunicar.

Getino, 0. (2005). Cine Argentino: entre lo posible y lo deseable. Buenos Aires, Argentina: Editorial Ciccus.

González Barroso, M. (2013). Identidad e interculturalidad en el cancionero infantil propuesto por la poetisa argentina María Elena Walsh (1930-2011). Dedica. Revista de Educação e Humanidades, 4, 199-219.

Halac, R. (23 de octubre de 1998). Tema Libre. Grandeza y decadencia de un género: el unitario de televisión. La Nación. Recuperado de https://www.lanacion.com.ar/lifestyle/grandeza-y-decadencia-de-un-genero-el-unitario-de-television-nid195604/

Heram, Y. (2009). La televisión argentina en diferentes contextos de cambios políticos, tecnológicos y culturales. Margen: revista de trabajo social y ciencias sociales, 54, 1-6.

Kesselan, H. y Pavlosvsky, B. (1989). La multiplicación dramática. Buenos Aires, Argentina: Ayllu.

Los miedos del pasado. (1 de junio de 2009). Resiste un archivo. Recuperado de http://resisteunarchivo.blogspot.com/2009/06/ los-miedos-del-pasado_01.html.
Lusnich, A. L. (2016). Formas de la dominación social en las ficciones alegóricas y metafóricas realizadas en épocas de la dictadura y la postdictadura en Argentina. IdeAs, 7, 1-15.

Lusnich, A. L. (2019). El devenir de las imágenes en los años de la última dictadura militar argentina: circulación y recepción de las ficciones hermético-metafóricas. Revista Fotocinema, 18, 249-272.

Murió Diana Álvarez, una de las grandes directoras de la TV local. (25 de junio de 2018). La Nación. Recuperado de https://www. lanacion.com.ar/espectaculos/television/murio-diana-alvarezuna-de-las-grandes-directoras-de-la-tv-local-nid2147286/

Pellettieri, 0. (1994). Teatro argentino contemporáneo (19801990). Buenos Aires, Argentina: Galerna.

Pellettieri, O. (Dir.). (2001a). Historia del teatro argentino en Buenos Aires. El teatro actual (1976-1998), Vol. 4. Buenos Aires, Argentina: Galerna.

Pellettieri, 0. (2001b). Teatro XX y la polémica entre realistas reflexivos y neovanguardistas. Cuadernos de Teatro XXI. En torno a Teatro $X X$, 9-19.

Quiroga, H. (2004). El tiempo del 'Proceso.' Conflictos y coincidencias entre políticos y militares. 1976-1983. Rosario, Argentina: Homo Sapiens-Fundación Ross.

Romano, S. (2007). Detrás de la pantalla: autoritarismo, censura y represión en los medios: Un estudio de caso, Córdoba 19731983. Prohistoria, 11, 61-89.

Rodríguez, L. (2015). Cultura y dictadura en Argentina (19761983). Estado, funcionarios y políticas. Anuario Colombiano de Historia Social y de la Cultura, 42(2), 299-325.

Sala, J. (2019). Territorios en disputa. Modernidad, figuración urbana y recepción de la reescritura fílmica de Los de la mesa 10. Studies in Spanish \& Latin American Cinemas, 16, 213 - 232.

Saló, G. (2003). ¿Qué es eso del formato? Como nace y se desarrolla un programa de televisión. Barcelona, España: Gedisa.

Schenquer, L. (2019). The uses of culture in the last Argentine dictatorship (1976-1983): from the post-dictatorship studies on repressive control to the most recent analyses on the construction of consensus. Latin American Perspectives, 20, 1-16.

Sirven, P. (1998). Quién te ha visto y quién TV. Buenos Aires, Argentina: De la Flor. 
Sticotti, J. (2017). De Canal Siete a ATC: dictadura, renovación tecnológica y apuesta por la televisión comercial (19781979). Revista Brasileira de História da Mídia, 6(01), 162-176.

Tarantuviez, S. (2007). La escena del poder. El teatro de Griselda Gambaro. Buenos Aires, Argentina: Corregidor.

Ulanovsky, C., Itkin. S. y Sirvén, P. (2006). Estamos en el aire. Historia de los medios de comunicación en la Argentina. Buenos Aires, Argentina: Emecé.

Varela, M. (2005). La televisión criolla. Buenos Aires, Argentina: Ariel.

Varela, M. (2016). Intelectuales y televisión: historia de una relación. PolHis. Revista Bibliográfica del Programa Interuniversitario de Historia Política, 1, 43-56.

Verón, E. (1993). La semiosis social. Fragmentos de una teoría de la discursividad. Barcelona, España: Gedisa.

Unitarios analizados en el artículo

Los especiales de ATC:

Susana Rinaldi. (4 de junio de 1982). Protagonizado por Susana Rinaldi, Horacio Ferrer, Amelita Blatar, Inés Rinaldi y Juan Carlos Cuacci. Dirección: María Herminia Avellaneda.

El atajo I y II. (24 de abril y 1 de mayo de 1981). Protagonizado por Osvaldo Terranova, Aldo Braga, Hugo Soto, Ana María Casó y Gloria Ugarte, entre otros actores. Autor: Adolfo Bioy Casares, con versión libre de José María Paolantonio. Dirección: Héctor Flores.

Proceso a cuatro monjas I y II. (1 y 17 de julio de 1981). Protagonizado por Tony Vilas, Silvia Bayle, Samy Zarember, Betiana Blum, Manuel Callau, Juana Hidalgo y Graciela Dufau, entre otros actores. Autor: Vladimiro Cajoli, con versión libre de Nelly Fernández Tiscornia. Dirección: Eduardo Ocana.

Quienes son mis padres. (1 de abril de 1981). Protagonizado por Aldo barbero, Tony Vilas, Martín Coria, Alberto Argibay, Alejandra Da Passano y Graciela Dufau, entre otros actores. Basado en la novela Proceso de familia, del escritor italiano Diego Fabbri, en versión libre de Máximo Soto. Dirección: Héctor Andrés Flores.
Nosotros y los miedos:

Miedo al presente. Aprender de nuevo. (s/f). Protagonizado por Alicia Aller, Graciela Dufau, Olga Zubarry, Aldo Barbero, Victor Laplace, entre otros actores. Idea y dirección: Diana Álvarez.

El espejo (Miedo a ver). (1982). Protagonizado por Graciela Dufau, Aldo Barbero, Ricardo Darín y Miguel Ángel Solá, entre otros actores. Autor: Jorge Maestro y Sergio Vaiman. Idea y dirección: Diana Álvarez.

Me quedo aquí, quieto (miedo al mundo). (1982). Idea y dirección: Diana Álvarez.

Los siete pecados capitales:

La pereza. (1982). Protagonizado por Eduardo Ayala, Aymará Bianquet, Thelma Biral y Nora Cullen, entre otros. Libro: Juan Carlos Cernadas Lamadrid.

Situación límite:

Ahora nos toca a nosotros. (23 de septiembre de 1983).Protagonizado por Oscar Martínez, Julio De Grazia, Soledad Silveyra y María Vaner. Autor: Nelly Fernández Tiscornia. Dirección: Alejandro Doria. Por qué? (11 de noviembre de 1983). Protagonizado por Victor Laplace, Graciela Dufau, Betiana Blum y Pablo Rago. Autor: Nelly Fernández Tiscornia. Dirección: Alejandro Doria.

El choque. (25 de noviembre de 1983). Protagonizado por Claudio García Satur, Haydée Padilla, Duilio Marzio y María Vaner. Autor: Nelly Fernández Tiscornia. Dirección: Alejandro Doria.

\section{Compromiso:}

Elegimos vivir. (1983). Autor: Ricardo Halac. Dirección: Rodolfo Hoppe La adopción. (1983). Dirección: Rodolfo Hoppe

\section{Contribución autoral}

a) Concepción y diseño del trabajo; b) Adquisición de datos; c) Análisis e interpretación de datos; d) Redacción del manuscrito; e) revisión crítica del manuscrito.

A. L. L. ha contribuido en a, b, c, d, e.

Editor responsable: L. D. 